\title{
ANALYSIS OF HEALTH STATUS OF WORKERS IN COAL INDUSTRY
}

\author{
M. Platikanova* \\ Department of Hygiene, Epidemiology and Infectious Diseases, Medical Faculty, Trakia University, \\ Stara Zagora, Bulgaria
}

\begin{abstract}
Purpose: Assessment of the health status of working operators in the substations in the coal industry. Material and methods: Prophylactic examinations were carried out on 82 workers responsible for ensuring the security of the power supply in the mines. Some basic indicators (range of prophylactic examinations, relative share of sick persons, structure of the momentary illness) were followed. A connection has been sought between the established deviations in the health status and the working environment factors, as well as the harmful habits.

Results: Diseases of the organs of the circulation (66.03\%) and "Endocrine diseases" (9.43\%) predominate in the registered pathology. The same share is the class "Diseases of the eye and its eye appendages" and "Diseases of the respiratory system" (5.66\%). Work environment factors are not directly related to health hazards. Smoking, alcohol consumption, obesity, stress are important to unlock some diseases.

Conclusions: Periodic medical examinations allow early detection of diseases and especially their timely treatment. On the basis of the health status analysis, the necessary health and medical activities, services and programs for the protection of the health of the employees can be developed, planned and implemented.
\end{abstract}

Key words: operators of electrical substations, mining industry, momentary morbidity, working conditions.

\section{INTRODUCTION}

The mining industry is a sector in Bulgaria, in which labor productivity at very close to the EU average, which significantly exceeds the average performance of other industries. The number of workers, particularly in the subsector - coal mining, is large. Due to these facts, one of the priorities of our country is their health. Early detection of health problems and risk factors that determine them, create favourable conditions for its preservation and recovery. To assess the health status of workers in this sub-sector (coal mining), it is necessary to examine the impact of harmful factors in the work environment on the development of occupational diseases and work accidents (1-6). Employees in good health are more productive and more highly

*Correspondence to: Magdalena Platikanova, 11 Armeyska Str, 6000 Stara Zagora, Bulgaria,Phone: +35942664240, E-mail: mplatikanova@abv.bg motivated. Their good health leads to reduced absences and disruptions in the work process (7-9).

Within the mining production of interest is the health of the operators of electric substations as their main activity is providing electric energy on the territory of mines.

The purpose of this study is to analyze the current morbidity in operators of electric substations. The main indicators are tracked scope of preventive examinations, relative share of sick persons, structure of current morbidity. A link between the identified deviations in health status and work environment factors and harmful habits is sought. Based on the results are suggested remedial measures to protect the health of workers. 


\section{MATERIALS AND METHODS}

Compulsory periodic medical examinations for operators of electric substations were conducted in accordance with the normative regulations (10). The following medical specialists were included: therapist, ophthalmologist, otorhinolaryngologist and gynecologist for the women. Clinicallaboratory studies include full blood count, erythrocyte sedimentation rate, C-reactive protein, cholesterol, blood sugar, triglycerides. The data from the studies were analyzed for each worker with construction of diagnosis. The results from the examinations are marked in the "Card for preventive check-up". It is used a questionnaire method to study the risk factors associated with lifestyle, working environment and genetic risk factors. The data obtained is processed by statistical methods (11). It was used the documentary - personal method that provides personal analysis of "momentary morbidity".

\section{RESULTS AND DISCUSSION}

Periodic medical check-ups are an option that allows early diagnosis of diseases and conduct timely and adequate treatment to prevent from becoming chronic and complex diseases. During the medical check-ups in the coal industry from 90 liable to research operators working in electric substations are covered 82, i.e. $91.1 \%$. The reviewed were 65 men and women - 17 at the age from 20 to 60 years. The structure by gender corresponds to the character and nature of work. It is known that age and gender have an influence on the level and characteristics of morbidity. Their distribution by age shows that both in women and men prevail workers in active working age from 36 to 55 years. The highest proportion of working women is in the age group from 46 to 55 years $(41.18 \%)$, followed by the group from 36 to 45 years $(35.29 \%)$. In men, the percentages are respectively $33.85 \%$ and $29.23 \%$ (Table 1). In terms of specialized work experience, most operators have worked this job for over 10 years (47.56\%). Second is the group of operators with experience from 6 to 10 years $(41.46 \%)$ (Table 2). The low percentage of people at the age of 20 to 35 years (14.63\%) and over $55(19.51 \%)$ and experience in the workplace to five years significantly influenced the results. Prolonged specialized experience in the workplace and increasing of the age are prerequisites for higher incidence of diseases and in particular the proportion of cases of chronic diseases. Women are more vulnerable to certain diseases due to the upcoming constitutional age and hormonal changes in the female body.

Comparing data from the anamnesis, examination and paraclinical tests at each operator found that $30.49 \%$ of examined persons are healthy. Persons with registered diseases are $57(69.51 \%)$, 46 of which are males $(80.70 \%)$ and 11 females $(19.30 \%)$.

Table 1. Structure of operators of electric substations passed a prophylactic examinationby age (\%)

\begin{tabular}{|l|c|c|c|c|c|c|}
\hline \multirow{2}{*}{ Age } & \multicolumn{2}{c|}{ Men } & \multicolumn{2}{c|}{ Women } & \multicolumn{2}{c|}{ Total } \\
\cline { 2 - 7 } & Number & \% & Number & \% & Number & \% \\
\hline 25 years & 0 & 0 & 1 & 5.88 & 1 & 1.22 \\
\hline 26 to 35 years & 8 & $12: 31$ & 3 & 17.65 & 11 & $13: 41$ \\
\hline 36 to 45 years & 19 & 29.23 & 6 & 35.29 & 25 & 30.49 \\
\hline 46 to 55 years & 22 & 33.85 & 7 & 41.18 & 29 & 35.37 \\
\hline over 55 years & 16 & 24.61 & 0 & 0 & 16 & $19: 51$ \\
\hline
\end{tabular}

Table 2. Structure of operators of electric substations passed a prophylactic examination by gender (\%)

\begin{tabular}{|l|c|c|c|c|c|c|}
\hline \multirow{2}{*}{ Specialized service } & \multicolumn{2}{c|}{ Men } & \multicolumn{2}{c|}{ Women } & \multicolumn{2}{c|}{ Total } \\
\cline { 2 - 7 } & Number & \% & Number & \% & Number & \% \\
\hline 5 years & 7 & 10.77 & 2 & 11.76 & 9 & 10.98 \\
\hline From 6 to 10 years & 27 & 41.54 & 7 & 41.18 & 34 & 41.46 \\
\hline Over 10 years & 31 & 47.69 & 8 & 47.06 & 39 & 47.56 \\
\hline
\end{tabular}

During the examinations are found 99 diseases, which means that for one person are registered 1.2 diseases.
Data from the registered cases during regular checkups are presented in Table 3. This shows that the largest total number of diseases is in class "Diseases of the eye and adnexa " - 49 
(49.50\%), followed by class "Diseases of the circulatory system" -35 (35.35\%). As the established diseases of the visual analyzer are at the expense of presbyopia, which is a physiological condition, we have examined the registered diseases after exclusion of presbyopia (Table 4). In this case, leading are diseases of circulatory system (66.03\%), followed by diseases of the endocrine system $(9.43 \%)$. On third place with the same share (5.66) is class "Diseases of the eye and adnexa" and class "Diseases of the respiratory system." Our results were confirmed by Cochrane et al., 1954; Coggon et al., 1998; Castranova et al., 2000; Article et al., 2015; Finkelman et al., 2017; Perret et al, 2017 who have conducted studies among workers in coal industry. The conclusions from them show that the work in this environment leads to lung diseases. Unlike our study they registered occupational diseases - different types of pneumoconiosis with initiation and progression of pulmonary fibrosis. Studies report about deepening of lung problems into COPD, emphysema, chronic bronchitis. Often are seen changes in the pleura (12-17). Ayar et al., 2016, made a study to evaluate ocular structures of workers by distributing them into three groups - healthy, with mild lung changes and diagnosed with pneumoconiosis. It is found that in healthy changes of the eye structures are less based on tests of peripapillary retinal nerve fiber layer (RNFL) thickness, choroidal thickness (CT), central macular thickness (CMT) and tear function tests (18).

Table 3. Structure of morbidity registered in prophylactic examinations diseases according to ICD - X revision

\begin{tabular}{|c|l|c|c|c|c|c|c|}
\hline \multirow{2}{*}{$\begin{array}{l}\text { № } \\
\text { Class }\end{array}$} & \multirow{2}{*}{ Name of the class ICD-X } & \multicolumn{2}{|c|}{ Men } & \multicolumn{2}{|c|}{ Women } & \multicolumn{2}{c|}{ Total } \\
\cline { 3 - 8 } & & Number & \% & Number & \% & Number & \% \\
\hline \multirow{2}{*}{ IV } & $\begin{array}{l}\text { Diseases of the endocrine system, } \\
\text { disorders of nutrition and } \\
\text { metabolism }\end{array}$ & 4 & 5.41 & 1 & 4 & 5 & 5.05 \\
\hline VI & Diseases of the nervous System & 2 & 2.70 & 0 & 0 & 2 & 2.02 \\
\hline VII & Diseases of the eye and adnexa & 34 & 45.95 & 15 & 60 & 49 & $\mathbf{4 9 . 5 0}$ \\
\hline VIII & Diseases of the ear and mastoid & 1 & 1.35 & 0 & 0 & 1 & 1.01 \\
\hline IX & Diseases of the circulatory system & 28 & 37.84 & 7 & 28 & 35 & $\mathbf{3 5 . 3 5}$ \\
\hline X & Diseases of the respiratory system & 2 & 2.70 & 1 & 4 & 3 & 3.05 \\
\hline XI & Diseases of the digestive system & 1 & 1.35 & 1 & 4 & 2 & 2.02 \\
\hline XIII & $\begin{array}{l}\text { Diseases of the musculoskeletal } \\
\text { system and connective tissue }\end{array}$ & 1 & 1.35 & 0 & 0 & 1 & 1.01 \\
\hline & Other & 1 & $21: 35$ & 0 & 0 & 1 & 1.01 \\
\hline
\end{tabular}

Table 4. Structure of morbidity registered in the prophylactic examination diseases (without presbyopia) according to ICD - $X$ revision

\begin{tabular}{|c|l|c|c|c|c|c|c|}
\hline \multirow{2}{*}{$\begin{array}{l}\text { No } \\
\text { Class }\end{array}$} & \multicolumn{1}{|c|}{ Name of the class ICD-X } & \multicolumn{2}{|c|}{ Men } & \multicolumn{2}{c|}{ Women } & \multicolumn{3}{c|}{ Total } \\
\cline { 3 - 8 } IV & $\begin{array}{l}\text { Diseases of the endocrine system, } \\
\text { disorders of nutrition and } \\
\text { metabolism }\end{array}$ & 4 & $\mathbf{9 . 5 2}$ & 1 & $\mathbf{9 . 0 9}$ & 5 & $\mathbf{9 . 4 3}$ \\
\hline VI & Diseases of the nervous system & 2 & $\mathbf{4 . 7 6}$ & 0 & 0 & 2 & 3.77 \\
\hline VII & Diseases of the eye and adnexa & 2 & $\mathbf{4 . 7 6}$ & 1 & $\mathbf{9 . 0 9}$ & 3 & $\mathbf{5 . 6 6}$ \\
\hline VIII & Diseases of the ear and mastoid & 1 & 2.38 & 0 & 0 & 1 & 1.89 \\
\hline IX & Diseases of the circulatory system & 28 & $\mathbf{6 6 . 6 6}$ & 7 & $\mathbf{6 3 . 6 4}$ & 35 & $\mathbf{6 6 . 0 3}$ \\
\hline $\mathbf{X}$ & Diseases of the respiratory system & 2 & $\mathbf{4 . 7 6}$ & 1 & $\mathbf{9 . 0 9}$ & 3 & $\mathbf{5 . 6 6}$ \\
\hline XI & Diseases of the digestive system & 1 & 2.38 & 1 & $\mathbf{9 . 0 9}$ & 2 & 3.77 \\
\hline XIII & $\begin{array}{l}\text { Diseases of the musculoskeletal } \\
\text { system and connective tissue }\end{array}$ & 1 & 2.38 & 0 & 0 & 1 & 1.89 \\
\hline & Other & 1 & 2.38 & 0 & 0 & 1 & 1.89 \\
\hline & Total & 42 & 100 & 11 & 100 & 53 & 100 \\
\hline
\end{tabular}


In women as well as in men, the primary nosological unit of the leading class "Circulatory Diseases" is arterial hypertension. Studies of Hendryx et al., 2009 report that the increase in diseases of the cardiovascular system and circulatory system and their specific forms such as heart attack, angina or coronary heart disease are noted in a relation with the coal industry (16). Perhaps the reasons for their occurrence are complex. On the one hand, they are related to the lifestyle, overweight, and hereditary factors. On the other hand, this can be explained by the nature of the work process of the operators (psychoemotional load, 12- hour work shifts, night shifts). Probably the reasons are the same for the diseases of the endocrine system, and in women these diseases can be related to the specifics of the nervous-endocrine regulation of the female organism. The primary nosological unit in this class of disease is noninsulin dependent diabetes. Men suffer equally diseases of respiratory, nervous system and have complaints from the visual analyzer (4.76\%). Significant workload of the visual analyzer also causes complaints and diseased in women. The relative share of these diseases is the same as that of the respiratory and digestive system (9.09). Irrational feeding associated with shift mode is likely to be a further contributing factor and to cause gastrointestinal problems to workers. Proof of this is a study by Massoudi et al., 1997. The authors report for cases of gastric cancer by linking the onset of the disease with the mentioned factors above (20).

Regardless of prolonged sitting posture with static load of the shoulder, neck and back complaints and diseases of musculoskeletal and connective tissue has been registered at only one operator - man. This shows that the work conditions in electric substations meet the requirements for safety and health at work. Other classes of diseases are represented by single cases and are comparable with the data for the country, region and sector. In some studies are identified cases of diseases of the hematopoietic tissue - leukemias, nonHodgkin's lymphoma, multiple myeloma. It is reported reported deaths from these diseases in workers in the coal industry $(20,21)$.

There are no occupational diseases registered. When filling out the cards for medical checkups are not reported new-found diseases.

Laboratory studies show a relatively high proportion of operators men with abnormal results- 53 (81.53\%). In 13 women (76.47\%) laboratory results are not in the normal range.

The completed questionnaire by operators submit additional information for their habits and lifestyle. This greatly contributes to the final analysis of the results of the screening, the connection of various diseases with lifestyle of operators and working conditions.

The results from the survey show that more than half of workers consider that they are under stress $(61.19 \%)$. It is reported a high rate of consumption of alcohol and smoking, respectively $47.56 \%$ and $40.24 \%$. For low physical activity reported $30.49 \%$ from the operators who were examined, which leads to overweight $(29.27 \%)$. Almost the same number consume foods with a high percentage of animal fats $(28.05 \%)$ and $36.58 \%$ put extra salt in their food (Table 5). Stress, psychoemotional load, shift work, physical inactivity, unhealthy diet, harmful habits influence on provocation of some diseases.

Table 5. Results from the survey of the operators of electric substations passed a prophylactic examination

\begin{tabular}{|l|c|c|c|c|c|c|}
\hline \multirow{2}{*}{ Sign } & \multicolumn{2}{c|}{ Men } & \multicolumn{2}{c|}{ Women } & \multicolumn{2}{c|}{ Total } \\
\cline { 2 - 7 } Stress & Number & \% & Number & \% & Number & \% \\
\hline Lack of physical activity & 38 & 58.46 & 13 & 76.47 & 51 & $\mathbf{6 1 . 1 9}$ \\
\hline Smoking & 19 & 29.23 & 6 & 35.29 & 25 & 30.49 \\
\hline Alcohol & 27 & 41.54 & 6 & 35.29 & 33 & $\mathbf{4 0 . 2 4}$ \\
\hline Greasy food & 38 & 58.46 & 1 & 5.80 & 39 & $\mathbf{4 7 . 5 6}$ \\
\hline Excessive use of salt & 23 & 35.39 & 0 & 0 & 23 & 28.05 \\
\hline Overweight & 22 & 33.85 & 8 & 47.06 & 30 & $\mathbf{3 6 . 5 8}$ \\
\hline
\end{tabular}


In conclusion we can say that the holding of periodic medical check-ups is essential because it allows early detection of diseases and their early treatment. The assessment and analysis of health determine the type and volume of health needs and on this basis can develop, plan and implement the necessary health and medical activities, services and programs to protect workers' health. The various health - educational events on topical health problems, increase the medical culture of workers on issues related to their health status.

\section{CONCLUSIONS}

1. A high range of prophylactic examinations is reported according to the world standards, which gives assurance for reliability of the analysis of the health status of the operators working in electric substations.

2. In more than half of the examined are registered diseases. In the structure of the morbidity, leading are the diseases from the class "iseases of the circulatory system", as a significant contribution to this has the hypertonic disease.

3. The second place is for class "Diseases of endocrine system ", and on third place with the same relative share is class "Diseases of the eye and adnexa" and class "Diseases of the respiratory system".

4. Factors of the working environment are not directly related to failures in the health.

5. Smoking, alcohol consumption, obesity, stress have an impact for causing some diseases.

6. The establishment of health and medical services and programs increase the medical culture of the workers and helps to protect their health.

\section{REFERENCES}

1. Dimitrova, T., Karaslavova, E., Donchev, N. Risk factors in subjects with acute myocardial infarct according to their professional affiliation. Cardiovascular diseases, 1:13-16, 2009.

2. Lubomirova, K., Petkov, D. Prevention and management of health risks (example from practice of occupational medicine in detergent company). Healthcare Management, 1:20-23, 2008.

3. Lubomirova, K., Kuneva, T., Popov, T., Panev, T. New data for the effects of carbon disulfide on endocrine status. Endocrinology, 3: 3-1, 2006.

4. Lubomirova K, Popov T, Panev T. Changes in lipid status in subjects exposed to carbon disulfide. Military medicine, 2: 27-30, 2006.

5. Velkova, D., Lubomirova, K. Neuropsychological effects and sense for health risk in exposure to chemical hazards. Healthcare Management, 3: 49-53, 2006.

6. Lubomirova, K. Health risk management at occupational exposure to carbon disulfide, Public health and Health Care in Greece and Bulgaria: the challenge of the crossborder collaboration. Papazissis publishers, Athens, 1159-1166, 2010.

7. National Program on Safety and Health at Work, 2010, <http://www.gli.government.bg/document/6 24>. (23.05.2012).

8. Prodanova, Y., Zlatanova, T., Cheshmedzhieva, A., Zlatanova, R. Healthy workplace - wasted funds or investment. First National Conference for the study and combat stress with international participation, Plovdiv, 331-335, 2003.

9. Vodenicharov, E., Lyapina, M., Tsvetkov, E., Badeva, E. Health risk in cottonspinning industry production. Problems of hygiene, 1-5, 2001.

10. Ordinance №3 from 28.02.1987 for the compulsory preliminary and periodic medical examinations of workers. Issued by the Minister of Public Health, amended, SG., issue 16 from 02.27.1987, issue 65 from 9.08.1991, issue 102 12/13/1994, issue 78 from 30.09.2005.

11.11.Vukov, M. Short introduction to biostatistics (lecture notes), 2010.

12.Castranova, V., Vallyathan, V. Silicosis and coal workers' pneumoconiosis. Environ Health Perspect, 108 (suppl. 4): 675-684, 2000.

13.Cochrane, A. L. Tuberculosis and coalworkers' pneumoconiosis. Br J Tuberc Dis Chest, 48 (4): 274-285, 1954.

14.Coggon, D., Taylor, A. N. Coal mining and chronic obstructive pulmonary disease: a review of the evidence, BMJ, 398-407, 1998.

15.Finkelman, R. B., Tian, L. The health impacts of coal use in China. International Geology Review, 579-589, 2017.

16.Perret, J. L., Plush, B., Lachapelle, P., Hinks, T.S.C., Walter, C., Clarke, P., et al. Coal mine dust lung disease in the modern era. Respirology, 22 (4): 662-670, 2017.

17.Salahuddin, D., Masood, A. K., Ghaznavi, M. , Khan, S. Health Issues of Coal Mine Workers in Pakistan. International Journal 
of Occupational Safety and Health, 5 (1): 7 10, 2015.

18.Ayar, O., Akdemir, M.O., Erboy, F., Yazgan, S., Hayri Ugurbas, S. H. Ocular findings in coal miners diagnosed with pneumoconiosis. Cutaneous and Ocular Toxicology, 114-117, 2016.

19.Hendryx, M., Zullig, K. J. Higher coronary heart disease and heart attack morbidity in Appalachian coal mining regions. Prev Med (Baltim), 49 (5): 355-359, 2009.
20.Morfeld, P., Lampert, K., Ziegler, H., Stegmaier, C., Dhom, G., Piekarski, C. Coal Mine Dust Exposure and Cancer Mortality in German Coal Miners. Appl Occup Environ Hyg., 12 (12): 909-14, 1997.

21.Massoudi, B. L., Talbott, E.O., Day, R.D., Swerdlow, S. H., Marsh, G. M., Kuller, L. $\mathrm{H}$. A case-control study of hematopoietic and lymphoid neoplasms: The role of work in the chemical industry. Am J Ind Med, 31 (1): 21-7, 1997. 